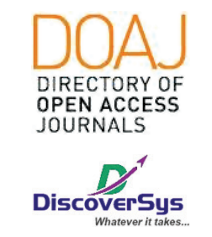

Published by DiscoverSys

\section{The prevalence of urinary incontinence in aged women in Peguyangan Village, District of Tag-Tag Kelod, Denpasar, Bali}

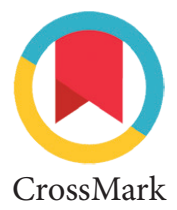

\author{
Diviya Batumalay, ${ }^{1 *}$ Yuliana, ${ }^{2}$ Nyoman Mangku Karmaya ${ }^{3}$
}

\section{ABSTRACT}

Background: Urinary incontinence (UI) is a significant health problem with considerable social and economic impact. Distinguishing between prevalence and incidence of incontinence is important. There are significant variations in the severity and impact of incontinence, and its severity, frequency, and predictability all need to be considered when evaluating its effects on patients, the degree of bother is particularly significant when determining who will need treatment. Incontinence may be a result of bladder dysfunction, sphincter dysfunction, or a combination of both, but large-scale studies are not designed to determine the etiology. Aim: To know the prevalence of $\mathrm{UI}$ in aged women in Peguyangan village, Denpasar, Bali.

Method: This is cross-sectional descriptive design conducted in Peguyangan Village Denpasar, Bali, in early July 2017. There were
79 of 94 aged women above 65 years involved in the survey using a questionnaire.

Result: In young women, the prevalence of incontinence is usually low, but prevalence peaks around menopause, with a steady rise there-after into later life. Although the prevalence of stress and mixed (stress and urge) incontinence is higher than urge incontinence, the latter is more likely to require treatment. In women, moderate and severe bother have a prevalence ranging from about $3 \%$ to $17 \%$. Severe incontinence has a low prevalence in young women but rapidly increases at ages 70 through 80 .

Conclusion: The prevalence is 0.076 .
'Program Studi Pendidikan Dokter, Fakultas Kedokteran, Universitas Udayana

${ }^{2}$ Bagian Anatomi Fakultas Kedokteran, Universitas Udayana/ RSUP Sanglah

*Corresponding: Diviya Batumalay, Program Studi Pendidikan Dokter, Fakultas Kedokteran, Universitas Udayana diviyabatumalaygounder@gmail. com

Received: 2018-04-09 Accepted: 2018-08-15 Published: 2019-04-01

Keywords: Urinary incontinence, stress, the prevalence

Cite This Article: Batumalay, D., Yuliana, Karmaya, N.M. 2019. The prevalence of urinary incontinence in aged women in Peguyangan Village, District of Tag-Tag Kelod, Denpasar, Bali. Intisari Sains Medis 10(1): 131-133. D0I: 10.1556/ism.v10i1.224

\section{INTRODUCTION}

Urinary Incontinence (UI) is known as enuresis or complaint of involuntary leakage of urine. It is a widespread problem among the elderly population. It can have a profound impact on the quality of life. Urinary Incontinence almost always results from an underlying treatable medical condition, unfortunately, is under-reported to medical practitioners. The term is usually under-reported as many women hesitate to seek help or report symptoms to medical practitioners. It is a prevalent condition with prevalence ranging from $10 \%$ to $34 \%$ especially amongst elderly. The bladder's ability, to fill and store urine required a functional sphincter and a detrusor. The bladder of infant contracts when urine is filled up to a particular volume of the bladder. This allows urination to be delayed. As the individual learns to control urination, bladder muscle contraction is prevented by constant inhibition from the cerebral cortex. Undesired bladder muscle contraction is a break in the neurological pathway from the brain to the bladder. It occurs when the bladder is irritated and neurological impulses to inhibit urination are insufficient to keep the bladder relaxed as it fills. Other medical problems lead by urinary incontinence are local skin irritation, rashes, and urinary infections. It can lead to pressure ulcers, in the debilitated and bed bound patients, which can increase the risk of osteomyelitis and sepsis. ${ }^{1}$

Psychological, physical and environmental causes may prevent voiding urine normally. Delirium, dementia, and psychosis can interfere with the ability to understand the sensation of bladder fullness. Frailty, injury, illness, or surgery can render many elderly patients immobile. Lack of easy access to toilets or prompt help is environmental causes of incontinence. Stress urinary incontinence is the most commonly diagnosed incontinence in women. ${ }^{2}$ The other risk factors included parity, obesity, chronic cough, depression, poor health, lower urinary tract symptoms, previous hysterectomy, and stroke. Globally, urinary incontinence affects at least one-third of women. Many women believe it to be untreatable even in western countries. For example, in India, where women usually do not seek treatment for their reproductive health problems. There is a "culture of silence" and low consultation rate among Indian women regarding such issues. ${ }^{3}$ 


\section{METHODS}

This is cross-sectional descriptive design conducted in Peguyangan Village Denpasar, Bali, in early July 2017. The sample is aged women above 65 years old and without any congenital diseases. There were 94 aged women above 65 years involved in the survey. Even though, only 79 of them who were participated in the study. The study was conducted using a questionnaire. Authors explained each question in the survey and let them answer as most of them did not know how to read and understand the questions without explanation.

\section{RESULTS AND DISCUSSION}

Peguyangan Village is one of the villages located in Denpasar City, especially Northern Denpasar District. The total population is approximately 3,600 families with 12,021 people consisting of 6,171 men and 5,850 women. The villagers work in various sectors such as trade, agricultural, healthcare, and economical industry. Most of the participant work in farming and shopkeepers.

Of the 79 participants that completed the questionnaire, 6 of them had urinary incontinence where the symptoms and criteria were suitable for the disease. Most of them didn't want to participate as they were shy and scared. Two of 6 aged women had been admitted and had a regular check-up in the healthcare centers. Another 4 of them didn't seek any health care center but consumed some traditional medicines which almost four years. In addition, there was no improvement, and they had had minimal side effects such as a headache, swelling, and muscle pain.

\section{Female workers}

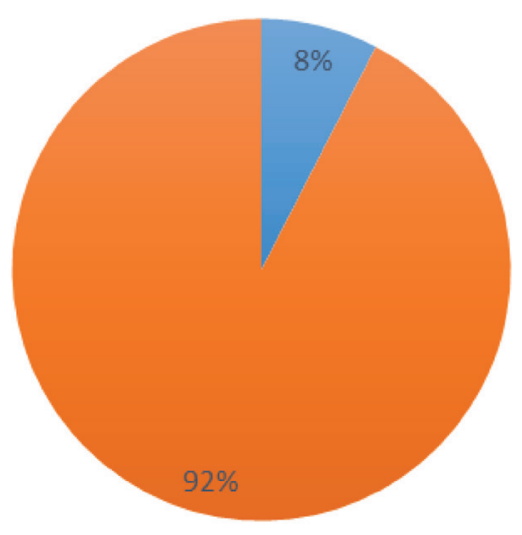

घrinary Incontinence

- Non-urinary incontinence

Figure 1 Data on the presence and absence of urinary incontinence in the subjects

\section{Number of aged women}

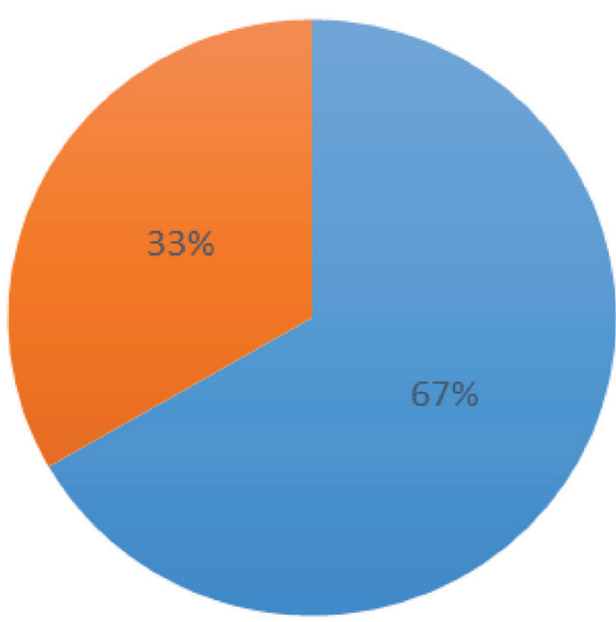

Stress averflow

Figure 2 Type of urinary incontinence suffered in the subjects

The level of activity that causes urinary leakage is categorized into few. Of the six observed samples, two samples indicated the leakage occurred during vigorous activity such as coughing, running, exercise, and sneezing. Another two samples occurred during moderate activity such as household chores and lifting things. There was one during light activity such as walking, bending, and rising. At least, one was observed without any activities.

Four of the six samples were categorized as under stress urinary incontinence. Three of them had leakage of urine during carrying things which are slightly bulky, one during sudden stress such as a cough, and the last two had urinary overflow incontinence where they had been admitted and treated in health care center as well as their condition was got better than before.

Based on the questionnaire, they were used few types of protection for urine leakage. The most common equipment were maxi pads which also knew as normal mensuration pad. Two of them were got it due to the leakage happened during vigorous and moderate activity. One only wearing underpants and mini pads. Another 2 was incontinence pads which were a proper pad that could withstand large quantity of urine as of the urinary overflow incontinence suffered. One of them did not use any protection and still stayed at home.

The quality of life is a multidimensional concept comprising of social, physical, and mental aspects of an individual. ${ }^{4}$ As such, interventions related to the quality of life of individuals are currently assessed taking into account the individual's 
perception about her wellbeing and expectations, including on a physical, social, emotional, and occupational level. ${ }^{5}$ UI, with its associated symptoms, can have a significant impact on the quality of life and a significant variety of perceptions and responses. It is often mediated by vulnerability to stress. So, in assisting women's health, it is necessary to identify problems and risk factors for the prevention, diagnosis, and treatment-related to a urinary loss in women. ${ }^{6}$ At the last findings, it was found that the prevalence of UI in women above 65 years old is 0.076 .

\section{CONCLUSION}

The prevalence of urinary incontinence in aged women above 65 years old in Peguyangan Village is 0.076 .

\section{REFERENCES}

1. Gibson, W, and Wagg. New horizons: Urinary Incontinence in Older People. Age and Ageing. 2014); 43(2): 157-163.

2. Neki, N. Urinary Incontinence in Elderly. Journal of Krishna Institute of Medical Sciences University. 2016; 5 (1): 5-13. ISSN 2231-4261

3. Linda, M. and Sobeski, K. Urinary Incontinence in the Older Adult; 2017: 1-20.

4. Timothy C. Davenport. Management of Urinary Incontinence. 2012; 37 (6): 346-61.

5. Silay, K and Akinci, S. Occult Urinary Incontinence in Elderly Women and Its Association with Geriatric Condition. 2016; 20: 447-51.

6. Coyne, K., Wein, A., Nicholson, S., Kvasz, M., Chen, C. and Milsom, I. Economic Burden of Urgency Urinary Incontinence in the United States: A Systematic Review. Journal of Managed Care Pharmacy. 2014; 20 (2): 130-40.

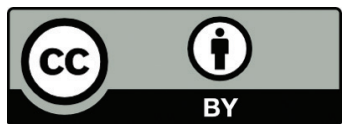

This work is licensed under a Creative Commons Attribution 